\title{
Laterally Displaced Pedicle Flap for the Management of Localised Gingival Recession: A Case Report
}

\author{
Dr. Kripa Shahi, ${ }^{1}$ Dr. Deepa Aryal, ${ }^{1}$ Dr. Surendra Man Shrestha ${ }^{1}$ \\ ${ }^{1}$ Department of Periodontology and Oral Implantology, Peoples Dental College and Hospital, \\ Shorakhutte, Kathmandu, Nepal
}

\begin{abstract}
Gingival recession, whenever presents with sensitivity, aesthetic problem, root caries or difficulty in plaque control may pose a challenge for clinicians. Among the various treatment modalities for root coverage, laterally displaced flap has been a promising treatment for isolated gingival recession with an adequate amount of donor tissue adjacent to the recipient site. This case report presents a case of successful root coverage where laterally displaced flap was employed for the management of gingival recession in mandibular central incisor with two and a half years follow up.

Keywords: Gingival recession; laterally displaced pedicle flap; root coverage.
\end{abstract}

\section{INTRODUCTION}

Gingival recession is defined as "The migration of the gingiva to a point apical to the cemento-enamel junction." Multifactorial aetiology of gingival recession includes inflammatory conditions, anatomic factors, or trauma. It may lead to aesthetic disharmony, defect progression, hypersensitivity, root caries, and unfavourable contour of gingival margin that limits plaque control, thus requiring root coverage. ${ }^{2}$ Grupe and Warren, in 1956, introduced laterally displaced pedicle flap (LDF) as "lateral sliding flap". ${ }^{3}$ This procedure is indicated in gingival recession limited to one or two teeth, narrow mesiodistal dimension, and with sufficient width, length and thickness of keratinised tissue adjacent to the area of recession. ${ }^{4}$

\section{CASE REPORT}

A 35-year-old male patient reported to the Department of Periodontology and Oral Implantology with a chief complaint of receding gum in lower front teeth region, for which he noticed sensitivity and expressed the fear of losing a tooth. Medical history was not significant. He reported the habit of

\section{Correspondence:}

Dr. Kripa Shahi

Department of Periodontology and Oral Implantology,

Peoples Dental College and Hospital,

Shorakhutte, Kathmandu, Nepal

email:me.kripashahi@gmail.com

\section{Citation}

Shahi K, Aryal D, Shrestha SM. Laterally Displaced Pedicle Flap for Management of Localized Gingival Recession: A Case Report. J Nepal Soc Perio Oral Implantol. 2020;4(7):35-8

DOI: https://doi.org/10.3126/jnspoi.v4i1.30902 tobacco consumption, which he used to place in his lower labial vestibule (3-4 times/day). He quit his habit five months back before he visited the hospital. On intraoral examination, positions of teeth were normal. Marginal tissue recession was not extending to mucogingival junction (MGJ) in relation to 41 and intraoral periapical radiograph (IOPA-R) revealed no loss of interdental bone, thus, noting to be Miller's class-I recession defect. ${ }^{5}$ Recession defect depth was $3.5 \mathrm{~mm}$ and width $2 \mathrm{~mm}$ (Figure1a,1b). Scaling, root planing was done and oral hygiene instructions were given. Six weeks after phase I therapy, patient was recalled for root coverage and written consent was taken.
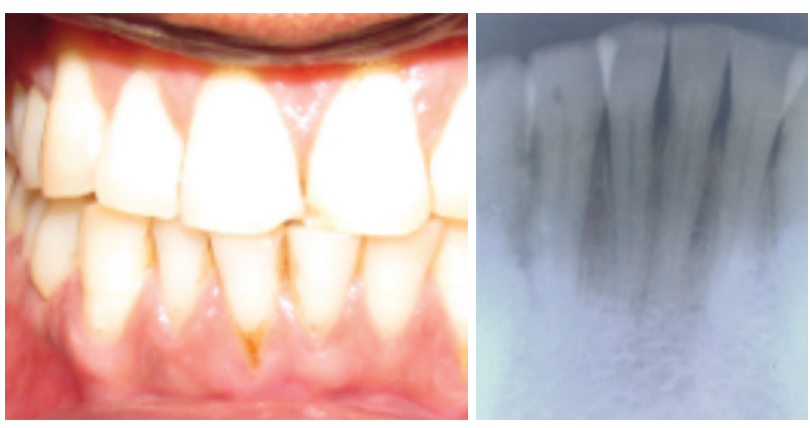

Figure1a: Gingival recession irt 41 and IOPAR.
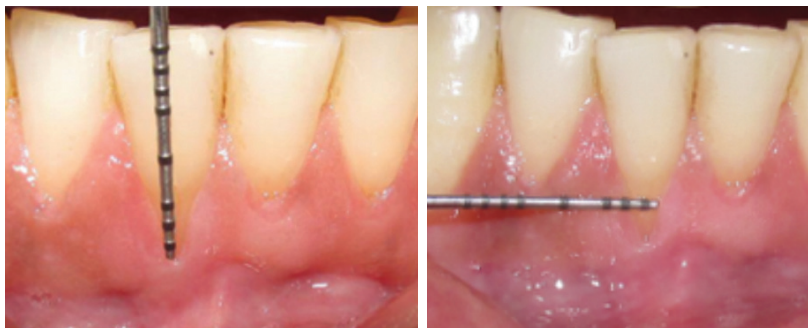

Figure1b: Recession depth- $3.5 \mathrm{~mm}$ and width - $2 \mathrm{~mm}$. 


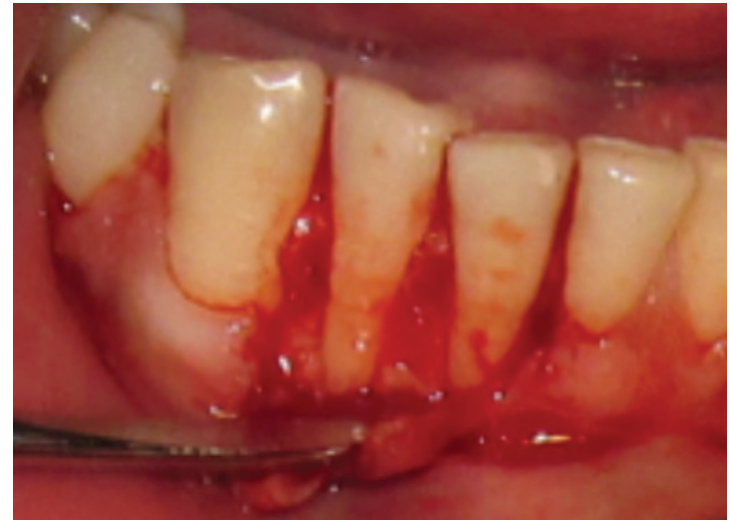

Figure2a: Pedicle flap reflection irt 42.

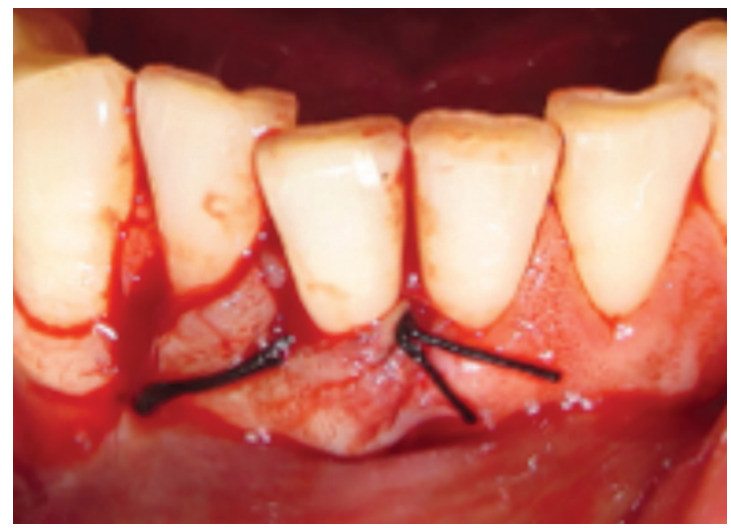

Figure 2c: Sling suture placed.

\section{Preparation of recipient site}

Intraorally, $0.2 \%$ chlorhexidine mouthrinse was given. The surgical area was anaesthetised by $2 \%$ lignocaine HCL with (1:200,000) epinephrine. Root planing was done to remove softened cementum and reduce the root convexity. Root was treated with a cotton pellet saturated with citric acid solution, pH 1.0 for 1 minute. Following adequate irrigation, a $\mathrm{V}$-shaped incision was given and de-epithelization was done with \#15-C scalpel blade around the area of gingival recession. External bevel incision was given in relation to 41 (mesial aspect).

\section{Pedicle flap preparation}

An internal bevel incision was given in gingival margin in relation to 41 (distal aspect) with the help of \#15-C scalpel blade. Full-thickness flap was reflected till mucogingival junction and extended far enough apically to alveolar mucosa to permit adequate flap mobility (Figure 2a). Vertical releasing incision was given at least $1 \frac{1}{2}$ teeth away from the recipient site at mesial line angle in relation to 43 in order to have width of pedicle flap $1 \frac{1}{2}$ times greater than the area of gingival recession. Passivity of the flap was checked by retracting lower lip and then cut back incision was given

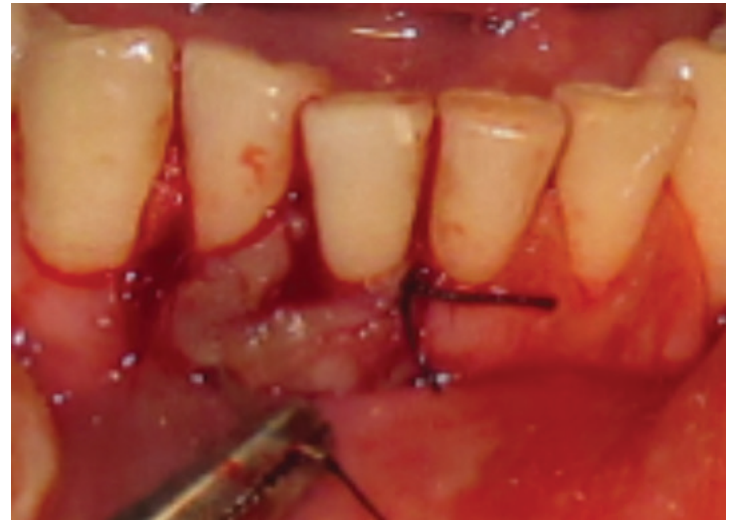

Figure 2b: Flap adaptation and suturing.

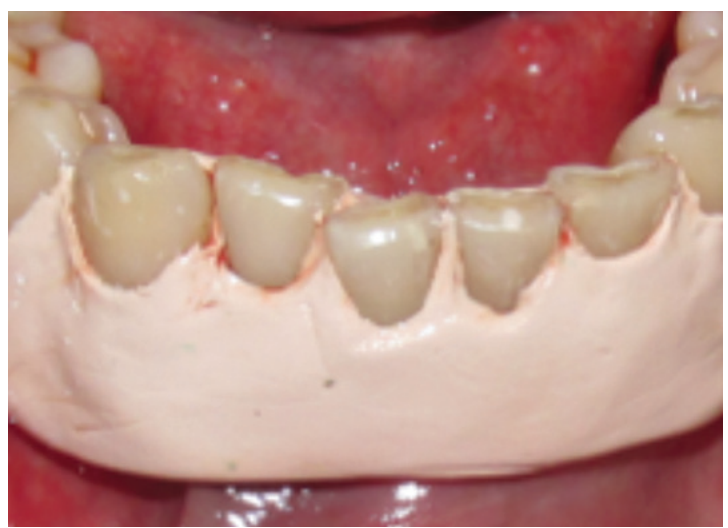

Figure 2d: Coe-pack placed.

at the base of flap to dissipate tension on flap. Flap was laterally displaced to cover the recession defect and sutured $2 \mathrm{~mm}$ coronal to cemento-enamel junction (CEJ) with the help of sling suture (4-0 silk suture, ETHICON) to pull papillae interproximally and hold the tissue tightly against neck of tooth (Figure 2b, 2c). Surgical site was then protected with Coe-pack (Coe Laboratories) (Figure 2d).

\section{Post-surgery}

Post-surgical instructions were given in written form. Medications were prescribed: Amoxicillin 500mg eight hourly for five days, Ibuprofen 400mg eight hourly for three days and Chlorhexidine mouthwash $0.2 \% 12$ hourly for 10 days. After 10 days of surgery, periodontal dressing and sutures were removed followed by irrigation with normal saline. Healing on both recipient and donor sites were satisfactory (Figure 3a). Similar results were observed at three months interval for a period of one year and at six months interval for two and a half years (Figure 3b, 3c, and 3d).

Satisfactory root coverage (71.42\%) was achieved at two and a half years follow up. Results were stable at both recipient and donor sites, along with an excellent colour matching with adjacent tissue. 


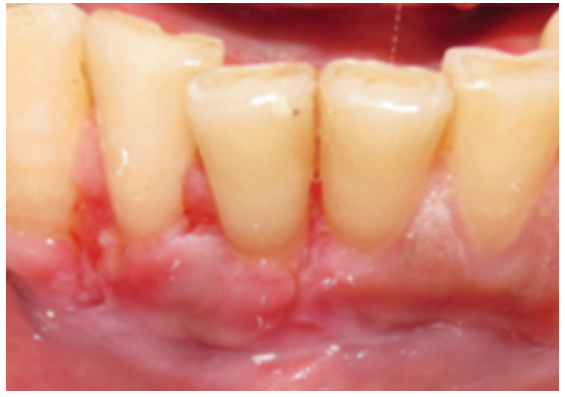

Figure 3a: Healing at 10 days.

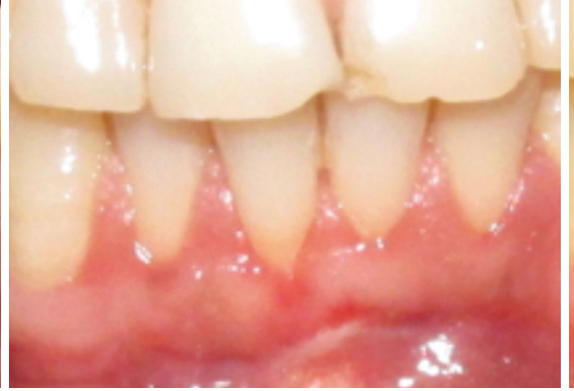

Figure 3b: Six months follow up.

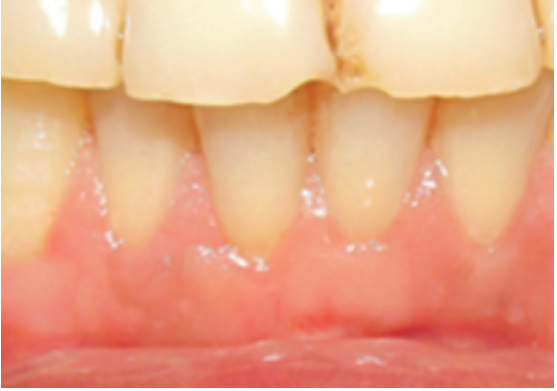

Figure 3c: One year follow up.
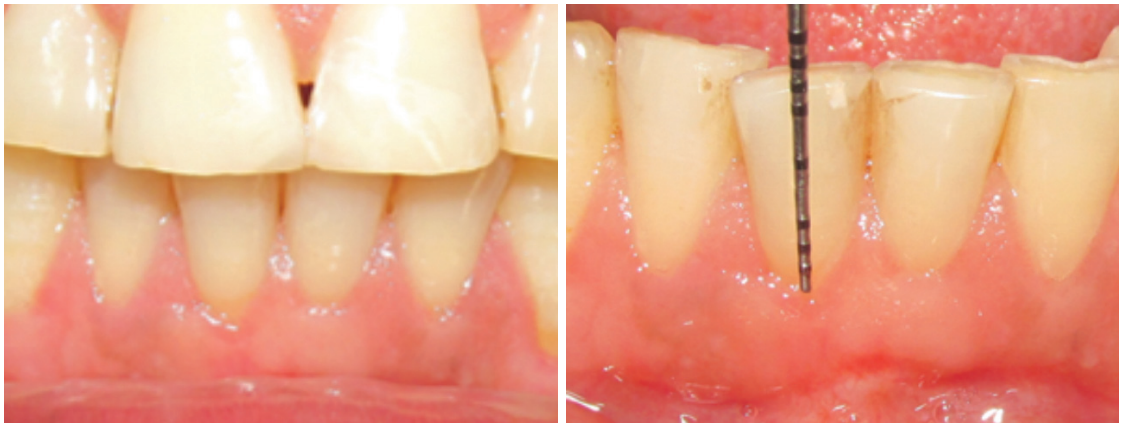

Figure 3d: Two and a half years follow up.

\section{DISCUSSION}

Various treatment modalities have been proposed for root coverage like free gingival autograft, free connective tissue autograft, pedicle autografts (coronally advanced flap and laterally displaced pedicle flap), sub-epithelial connective tissue graft, guided tissue regeneration, pouch, and tunnel technique.6 Success of periodontal therapy is based on the use of predictable surgical procedures and laterally displaced pedicle flap has been described as one of such procedures. $^{7}$ The advantages with this technique are single surgical site, good vascularity of the pedicle flap and colour match. ${ }^{4}$ Possibility of recession, dehiscence or fenestration of donor site, root coverage limited to one or two teeth, need of adequate amount of adjacent keratinised attached gingiva are major disadvantages of laterally displaced pedicle flap. ${ }^{4,8}$ In this case, laterally displaced pedicle flap was chosen as the recession was limited to a single tooth with the narrow mesiodistal dimension having sufficient keratinised gingival adjacent to the area of gingival recession.

Various modifications of laterally displaced pedicle flap have been advocated. Staffileno (1964) proposed partialthickness flap and Grupe (1966) gave submarginal incision, a conservative approach to prevent a recession in donor sites.8 However, laterally displaced full-thickness flaps have the best prognosis as compared to the partial-thickness flaps. Lateral displaced flaps have success rate less than other technique. Corn (1964) introduced cutback incision to release flap tension and pedicle flap from edentulous area. ${ }^{9}$ Knowles and Ramfjord used free autogenous gingival graft to cover the donor site. ${ }^{4}$ In this case report, LDF using classically-described technique was employed. Length of recession was measured from CEJ to gingival margin in deepest part of recession. Pre-operatively, recession depth was $3.5 \mathrm{~mm}$ which improved to $2.5 \mathrm{~mm}$ and was stable at the end of two and a half years. Satisfactory immediate results obtained with LDF was maintained for a long duration, as similar to the study done by Caffesse and Guinard.10 Percentage of root coverage obtained was $71.42 \%$, which is similar to the success rate $72.42 \%$ as obtained by H.Smukler. ${ }^{7}$ Full-thickness mucoperiosteal flap was raised which enhances the vascular supply of the pedicle and hence the end result of root coverage. Residual recession of $1 \mathrm{~mm}$ on recipient site has been observed for which gingival biotype, post-operative shrinkage, slippage, tension on pedicle flap, or brushing technique could have been the reason.

\section{CONCLUSION}

Above technique gave a successful outcome, where patient was relieved of sensitivity and overcame the psychological fear of losing his tooth with optimal esthetic result thus, one can consider laterally displaced pedicle flap as an effective treatment modality for root coverage.

\section{Conflict of interest: None.}




\section{REFERENCES}

1. AAP's Glossary of Periodontal Terms. American Academy of Periodontology 2012. http://members.perio.org/libraries/glossary?ssopc=1

2. Oates TW, Robinson M, Gunsolley JC. Surgical therapies for the treatment of gingival recession. A systematic review. Ann Periodontol. 2003;8(1):303-20.

3. Grupe HE, Warren RF. Repair of gingival defects by a sliding flap operation. J Periodontol. 1956;27(2):92-5.

4. Cohen ES. Atlas of cosmetic and reconstructive periodontal surgery.3rd ed. Ontario, Canada: BC Decker Inc.; 2007. p65.

5. Miller PD. A classification of marginal tissue recession. Int J Periodontics Restorative Dent. 1985;5(2):8-13.

6. Newman MG, Takei HH, Klokkevold PR, Carranza FA. Carranza's Clinical Periodontology.11th ed. St. Louis Mosby: Saunders Elsevier; 2012. p1504.

7. Smukler H. Laterally positioned mucoperiosteal pedicle grafts in the treatment of denuded roots. A clinical and statistical study. J Periodontol. 1976;47(10):590-5.

8. Grupe HE. Modified technique for the sliding flap operation. J Periodontol. 1966;37(6):491-5.

9. Wilderman MN, Wentz FM. Repair of a dentogingival defect with a pedicle flap. J Periodontol. 1965;36:218-31.

10. Caffesse RG, Guinard EA. Treatment of localized gingival recessions. Part IV. Results after three years. J Periodontol. 1980;51(3):167-70. 